\title{
Fluorographic Detection of Radioactivity in Polyacrylamide Gels with the Water-Soluble Fluor, Sodium Salicylate ${ }^{1}$
}

\author{
John P. Chamberlain \\ Division of Biological Sciences, University of Michigan, Ann Arbor, Michigan 48109
}

Received March 13, 1979

\begin{abstract}
Sodium salicylate has been found to serve as a satisfactory fluor for enhanced detection of radioactivity in polyacrylamide gels. The compound is inexpensive. water soluble. penetrates rapidly into gels, and gives linearity and sensitivity comparable to diphenyl oxazole.
\end{abstract}

Fluorography has recently achieved widespread usage for detection of radioactivity in polyacrylamide gels $(1,2)$. Aqueous gels are equilibrated with dimethyl sulfoxide (DMSO), ${ }^{2}$ impregnated with fluor PPO dissolved in DMSO, soaked in water to remove DMSO, dried, and exposed to X-ray film at $-70^{\circ} \mathrm{C}$. The use of DMSO is necessitated by PPO's insolubility in water. $\beta$ particles, instead of directly interacting with the photographic emulsion as in conventional autoradiography, cause the fluor to produce multiple photons which activate the film. Fluorography increases the sensitivity for ${ }^{14} \mathrm{C}$ and ${ }^{35} \mathrm{~S}$ about 10 -fold, and permits detection of ${ }^{3} \mathrm{H}$ which cannot be detected with conventional autoradiography. The response is linear if the $X$-ray film is presensitized with a flash of visible light (2).

For all its advantages, the current method has several drawbacks. It is somewhat tedious, requiring $5 \mathrm{~h}$ from the start of DMSO equilibration to the end of the water soak. It is also costly, even if excess PPO is recrystallized and reused.

For these reasons, I have sought a rapid, inexpensive method employing a water-sol-

\footnotetext{
${ }^{1}$ Supported by a grant from the National Science Foundation.

${ }^{2}$ Abbreviations used: DMSO, dimethyl sulfoxide: PPO, diphenyl oxazole; SDS. sodium dodecyl sulfate.
}

uble fluor. The compound must fluoresce at high concentrations since, unlike conventional liquid scintillation counting, the fluor itself must serve as the primary absorber of $\beta$ particles. All the above requirements are satisfied by sodium salicylate.

\section{METHODS}

Sodium salicylate (USP) was obtained commercially or made from salicylic acid (reagent grade or USP) by solution in the presence of equimolar $\mathrm{NaOH}$ and adjustment to $\mathrm{pH} 5-7 .{ }^{35} \mathrm{~S}$ - or ${ }^{3} \mathrm{H}$-labeled yeast or sea urchin embryo proteins were mixed with $10 \%$ acrylamide solutions before polymerization into gels $1.5 \mathrm{~mm}$ thick. Gel squares $2 \times 2 \mathrm{~cm}$ were soaked at room temperature for various times in $10 \mathrm{vol}$ of sodium salicylate solutions of different concentrations, or treated with DMSO-PPO (1), dried beneath acetate sheets at about $80^{\circ} \mathrm{C}$ under vacuum on a Bio-Rad drier, and exposed to preflashed (2) Kodak X-Omat X-ray film (XR5) at $-70^{\circ} \mathrm{C}$. Preliminary experiments used Kodak Royal-X film developed with ethol blue. Films were scanned with white light on a Joyce-Loebl microdensitometer. SDS-slab gel electrophoresis of ${ }^{3} \mathrm{H}$ - and ${ }^{35} \mathrm{~S}$-labeled yeast proteins employed $10 \%$ acrylamide gels $1.5 \mathrm{~mm}$ thick and the buffer systems of LeStourgeon and Rusch (3). 


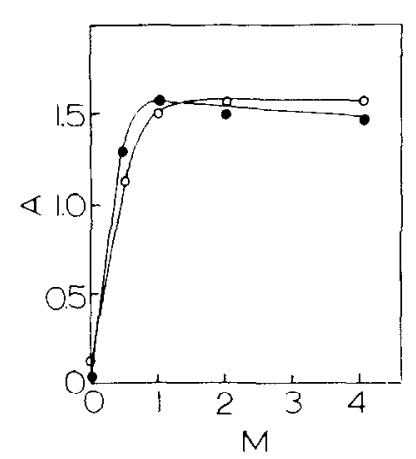

FIG. 1. Effect of sodium salicylate concentration on film darkening. Gel squares containing ${ }^{3} \mathrm{H}$ - or ${ }^{35} \mathrm{~S}$-labeled yeast proteins were soaked $1 \mathrm{~h}$ in sodium salicylate solutions of different concentrations, dried, and exposed to preflashed $\mathrm{X}$-ray film at $-70^{\circ} \mathrm{C}$. Absorbance of the developed film was determined with a Joyce-Loebl microdensitometer. $(O-O)^{35} \mathrm{~S} ;(\mathbf{O}-\mathbf{0})^{3} \mathrm{H}$

\section{RESULTS}

In preliminary experiments ${ }^{3} \mathrm{H}$-labeled compounds were mixed with aqueous solutions of fluorescent compounds at various concentrations, spotted on filter paper, airdried, and exposed to Royal-X film, an extremely fast panchromatic film. Familiar fluorescent compounds such as fluorescein and rhodamine produced no film darkening, no doubt because they do not fluoresce at concentrations high enough for thern to absorb $\beta$ particles efficiently. Sodium salicylate, however, produced film darkening at concentrations up to $4 \mathrm{M}$, the highest tested. Viewing under ultraviolet light confirmed an intense blue fluorescence even at high concentrations. Neither ${ }^{3} \mathrm{H}$-labeled compounds (except at extremely high concentrations) nor salicylate alone produced film darkening. Reexposure with XR-5 X-ray film gave even greater darkening, and was used in subsequent experiments. This film, wellmatched to PPO's fluorescence spectrum (av $=3745 \AA$ ), is apparently also well suited to work with sodium salicylate with average fluorescence emission of $4089 \AA$ in ethanol solution (4).

To determine the optimum salicylate concentration for impregnation into polyacryl- amide gels, gel squares polymerized in the presence of ${ }^{3} \mathrm{H}$ - or ${ }^{35} \mathrm{~S}$-proteins were soaked in sodium salicylate solutions of various concentrations for $1 \mathrm{~h}$, dried, and exposed to X-ray film. Figure 1 shows that a plateau of maximal film darkening is obtained with salicylate concentrations from 1 to $4 \mathrm{M}$. Gels soaked in 2 and $4 \mathrm{M}$ salicylate did not dry to a hard consistency, but remained somewhat rubbery. For this reason and for economy, 1 m solutions were used subsequently.

To determine the optimal impregnation time, gel squares containing ${ }^{3} \mathrm{H}$-proteins were soaked in $1 \mathrm{M}$ sodium salicylate for various times. Figure 2 shows that maximal film darkening occurs after 15-30 min of soaking. Darkening decreased slightly with prolonged soaking $(5 \%$ less after $2.5 \mathrm{~h}$ ). Although protein samples were dialyzed before polymerization into gels, diffusion of low molecular weight radioactive components out of the gels during soaking might account for this minor loss. From this data, a soaking time of $30 \mathrm{~min}$ was chosen for subsequent work.

To determine whether salicylate gives a linear relationship between amount of film darkening and radioactivity, and to compare its sensitivity with that of PPO, gels polym-

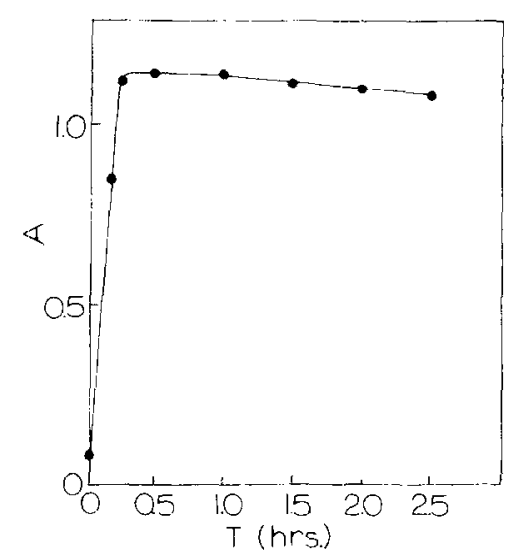

FIG. 2. Effect of sodium salicylate treatment time on film darkening. Gel squares containing ${ }^{35} \mathrm{~S}$-labeled yeast proteins were soaked in $1 \mathrm{M}$ sodium salicylate for various times. X-Ray film was exposed and analyzed as in Fig. 1. 
erized with various concentrations of ${ }^{3} \mathrm{H}$ and ${ }^{35} \mathrm{~S}$-proteins were either soaked in $1 \mathrm{M}$ sodium salicylate for $30 \mathrm{~min}$ or processed with DMSO-PPO according to the methods of Bonner and Laskey (1). Figure 3 shows that both methods produce linearity and comparable sensitivity.

To assess the quality of X-ray film images produced by the two methods, serial dilutions of ${ }^{3} \mathrm{H}$ - and ${ }^{35} \mathrm{~S}$-yeast proteins were electrophoresed in duplicate on SDS-slab gels, fixed in 10\% acetic acid, and processed with DMSO-PPO or sodium salicylate on time schedules ending simultaneously so as to permit parallel drying. Acid-fixed gels were soaked in water for $30 \mathrm{~min}$ prior to sodium salicylate treatment to prevent precipitation of salicylic acid. Figure 4 shows that both methods produce bands of comparable intensities at the various protein sample dilutions. However, the bands seem slightly more diffuse with salicylate as compared to those with DMSO-PPO. This apparently is not due to protein diffusion.

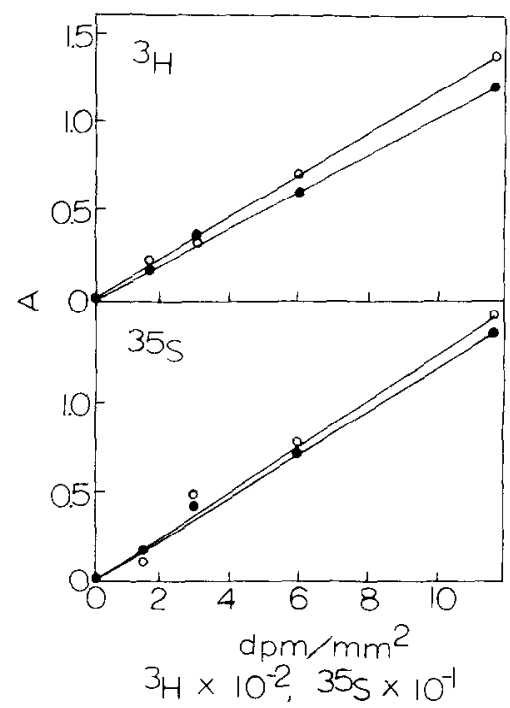

FIG. 3. Effect of isotope concentration on film darkening by sodium salicylate- or PPO-treated gels. Gel squares containing different concentrations of ${ }^{3} \mathrm{H}$ or ${ }^{35} \mathrm{~S}$-labeled yeast proteins were soaked in $1 \mathrm{M}$ sodium salicylate for $0.5 \mathrm{~h}$ or in $22 \%$ (w/v) PPO in DMSO for $3 \mathrm{~h}$. X-Ray film was exposed and analyzed as in Fig. 1. $(\mathrm{O}-\mathrm{O})$ Sodium salicylate:

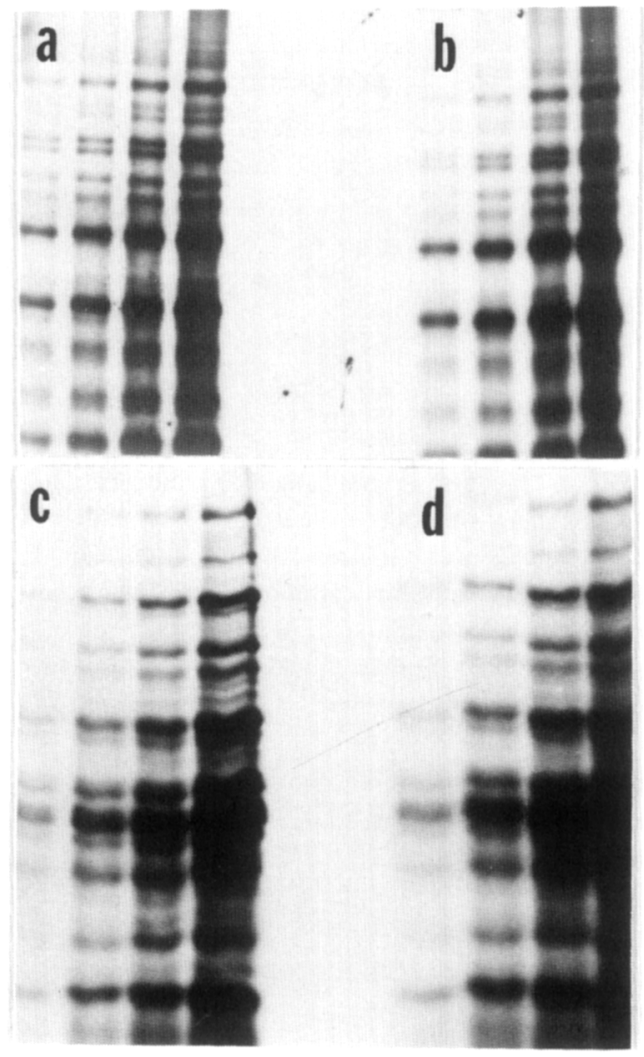

FIG. 4. Comparison of fluorographic images of labeled protein bands separated by electrophoresis. "is $S$ - and ${ }^{3} \mathrm{H}$-yeast proteins in onefold serial dilutions were separated by SDS-gel electrophoresis, treated with PPO-DMSO or sodium salicylate as in Fig. 3, dried, and exposed to $X$-ray film at $-70^{\circ} \mathrm{C}$ for $20 \mathrm{~h}$. (a) ${ }^{32} \mathrm{~S}$ in PPO; (b) ${ }^{i 5} \mathrm{~S}$ in salicylate: (c) ${ }^{3} \mathrm{H}$ in $\mathrm{PPO}$; (d) ${ }^{2} \mathrm{H}$ in salicylate.

since gels exposed to X-ray film at room temperature, where fluorography is not effective and film darkening results solely from interaction of $\beta$ particles with the emulsion, show equally sharp bands with both methods.

\section{STANDARD METHOD}

1. Soak gel in $10 \mathrm{vol}$ of $1 \mathrm{M}$ sodium salicy-

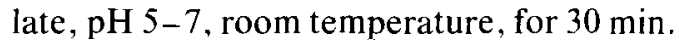
Lay on $\mathrm{H}_{2} \mathrm{O}$-wetted Whatman $3 \mathrm{MM}$ paper.

2. Dry at about $80^{\circ} \mathrm{C}$ under vacuum (aspirator) for $2 \mathrm{~h}$ under an acetate sheet.

3 . Remove acetate sheet, expose to preflashed (2) Kodak XR-5 X-ray film at $-70^{\circ} \mathrm{C}$. 


\section{DISCUSSION}

Gels fixed in acid and those stained with dyes in acid solution should be soaked in about $20 \mathrm{vol}$ water for $\mathbf{3 0}$ min prior to treatment to prevent precipitation of salicylic acid. Coomassie-stained protein bands are retained after salicylate treatment and drying.

Gels dried under the Mylar sheet supplied with the Bio-Rad drier stick badly to the Mylar. Acetate sheets can be easily removed if the gel is thoroughly dry and cool. If desired. exposure to $X$-ray film can be made through the acetate sheet with satisfactory results, but artificial blotches of unknown origin sometimes darken the film. Sodium salicylate sublimes at high temperatures, and although no loss has yet been detected with 2-h drying times at $80^{\circ} \mathrm{C}$, extended times or higher temperatures would appear undesirable.

Sodium salicylate solutions have been reused twice on the same day with good results. Solutions turn brown after prolonged standing (several weeks), presumably due to oxidation. If it is desirable to reuse the salicylate after several days, it should be recrystallized as salicylic acid soon after use by addition of equimolar $\mathrm{HCl}$, washing with water on a Buchner funnel, and drying overnight with suction.

Neither the PPO-DMSO nor the salicylate method are without potential hazard. None have any known mutagenicity or carcinogenicity. DMSO readily penetrates the skin and can cause skin irritation, urticaria, nausea, vomiting, cramps, chills, drowsiness, and fatal allergic reaction (5). PPO is of only moderate toxicity $\left(\mathrm{LD}_{50}=750 \mathrm{mg} /\right.$ $\mathrm{kg}$ ) when given intraperitoneally in mice (6), but could be more so when dissolved in a penetrant carrier such as DMSO. Salicylate is also moderately toxic $\left(\mathrm{LD}_{30}=780 \mathrm{mg} / \mathrm{kg}\right.$ intraperitoneally, $1600 \mathrm{mg} / \mathrm{kg}$ orally in rats (6)). It is a teratogen, but only at near-lethal levels (7). However, it can elicit allergic reactions such as a asthma, urticaria, angioneurotic edema, and serum sickness, but probably not true anaphylaxis. It is also readily absorbed through the skin (8). Thus gloves should be worn while handling gels in salicylate, and persons with known aspirin sensitivity should be especially cautious.

The slight diffuseness of radioactive gel bands with salicylate fluorography is not understood. It is not due to protein diffusion, and it is unlikely to be caused by an emission-absorption cascade effect since the emission and absorption spectra in ethanol solution do not overlap (6). However, this may not be the case for the solid state employed here. This slight diffuseness notwithstanding. fluorography with sodium salicylate provides a rapid and inexpensive alternative to the PPO-DMSO method.

\section{REFERENCES}

1. Bonner, W. M.. and Laskey, R. A. (1974) Eur. J. Biochem. 46, 83-88.

2. Laskey, R. A., and Mills, A. D. (1975) Eur. J. Biochem. 56, 335-341.

3. LeStourgeon, W. M., and Rusch, H. P. (1973) Arch. Biochem. Biophys. 155, 144-158.

4. Beriman, I. B. (1965) Handbook of Fluorescence Spectra of Aromatic Molecules, Academic Press, New York.

5. Stecher, P. G. (1968) The Merck Index. 8th ed., p. 378 , Merck \& Co., Rahway, N. J.

6. Christensen, H. E. (1973) The Toxic Substances List, U. S. Dept. HEW, Rockville, Md.

7. Warkany, J., and Takacs, E. (1959) Amer. J. Puthol. 35, 315-331.

8. Dukes, M. N. G., ed. (1975) Meyler's Side Effects of Drugs, Vol. 8, pp. 154-176, Excerpta Medica. Amsterdam. 